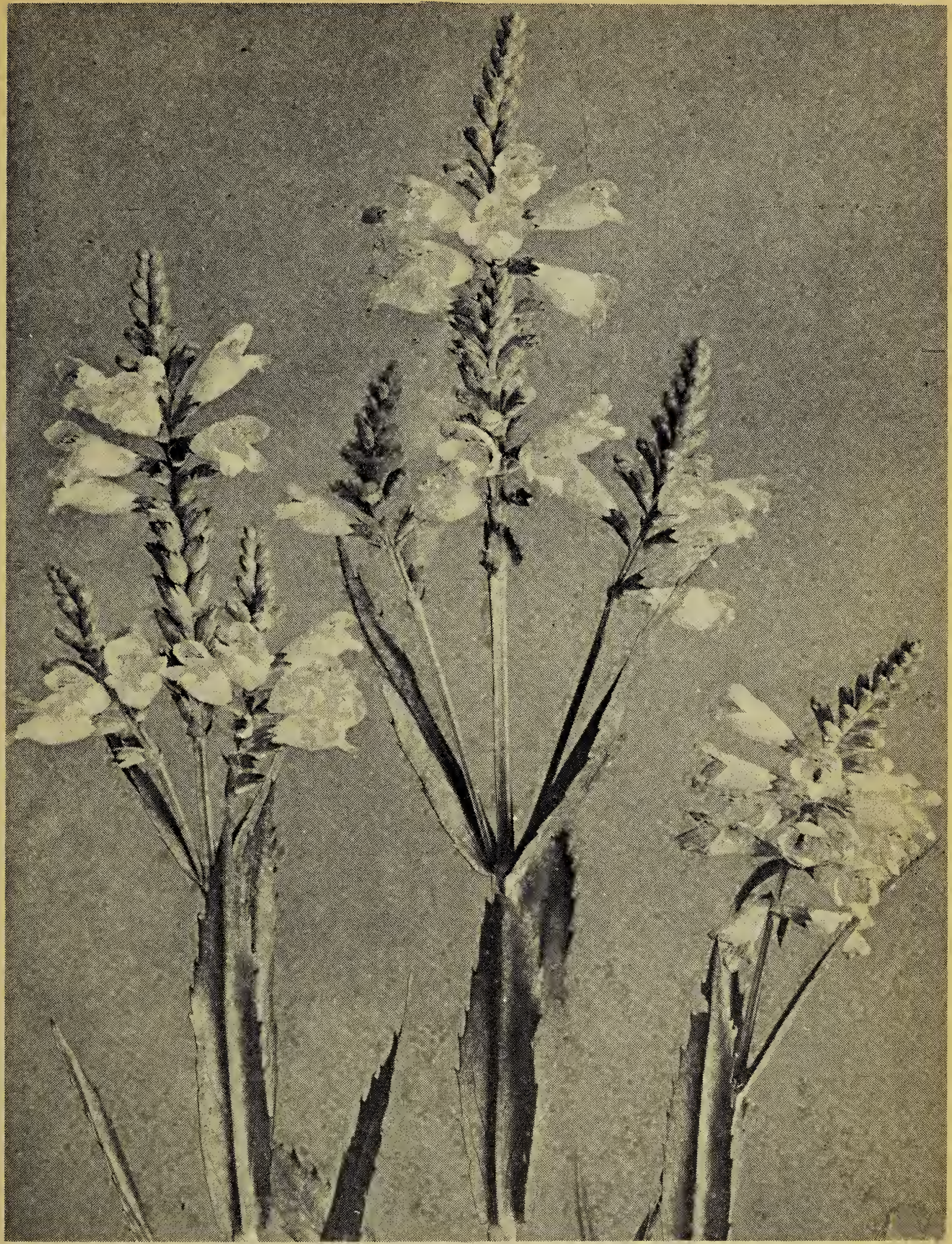

Photo by W. C. McCalla

\title{
False Dragonhead
}

\section{Dracacephalum nuttallii Britt}

This Mint Family plant has square stems which are stiffly erect and from one to three feet tall. The flowers are a beautiful rcse-pink or purple. The plant grows in damp thickets and along the banks cf streams. It is widespread from east to west but it is not often abundant. It is hoped that we may see it growing in the Greenwater Provincial Park this June. 